\title{
ERRATUM
}

\section{Erratum to: Literacy Skills and Calculated 10-Year Risk of Coronary Heart Disease}

Laurie T. Martin, ScD MPH' , Matthias Schonlau, $P h D^{7,2}$, Ann Haas, $\mathrm{MS}^{7}$,

Kathryn Pitkin Derose, $P h D, M P H^{7}$, Rima Rudd, $S c D^{3}$, Eric B. Loucks, $P h D^{4}$, Lindsay Rosenfeld, SCD SCM ${ }^{5}$, and Stephen L. Buka, SCD ${ }^{4}$

${ }^{1}$ RAND Corporation, Arlington, VA, USA; ${ }^{2}$ DIW, Berlin, Germany; ${ }^{3}$ Harvard School of Public Health, Boston, MA, USA; ${ }^{4}$ Brown University School of Public Health, Providence, RI, USA; ${ }^{5}$ Northeastern University, Boston, MA, USA.

J Gen Intern Med 26(2):228

DOI: $10.1007 / \mathrm{s} 11606-010-1557-9$

(c) Society of General Internal Medicine 2010

\section{Erratum to: J Gen Intern Med}

\section{DOI 10.1007/s11606-010-1488-5}

he fourth author's surname was incorrectly captured in the original publication. Abbreviated correctly, the fourth author's name is Derose, $\mathrm{K}$. P.

The online version of the original article can be found at http://dx.doi. org/10.1007/s11606-010-1488-5.

Published online October 30, 2010 